\title{
Aspectos relevantes sobre la adquisición de proyectos mineros en el Perú
}

\author{
Ricardo de la Piedra Calle \\ Abogado por la Universidad de Lima. \\ Ex miembro de ADVOCATUS.
}

SUMARIO:

I. Introducción.

II. Tipos de adquisición:

1. Adquisición vía contrato de transferencia de concesiones del proyecto minero

1.1. Sobre el contrato de transferencia de derechos mineros;

1.2. Dispocisiones formales y generales;

1.3. Sobree la rescisión por lesión y el derecho de retracto;

1.4. Sobre la verificación regulatoria de derechos y condiciones asociadas a las condiciones del proyecto;

1.5. Tipo de adquisición;

1.6. Puntos claves sobre la adquisición mediante contrato de transferencia de derechos mineros

2. Adquisición de la sociedad titular del proyecto minero:

2.1. Proceso de due diligence;

2.2.Condiciones de compraventa de acciones;

2.3. Adquisición parcial: pacto de accionistas;

2.4. Puntos clave.

3. Inversión conjunta en el proyecto minero:

3.1. Proceso de due diligence;

3.2. Sobre el pacto de accionistas;

3.3. Puntos clave.

III. Conclusiones. 


\section{INTRODUCCIÓN}

A lo largo de las últimas dos décadas, muchos peruanos, sin importar su profesión, condición social, económica, u otros factores, han notado el denominado"boom" de la minería en el Perú. No sólo las personas naturales, sino personas jurídicas que prestan servicios vinculados al negocio minero han sentido también el incremento en sus labores. Específicamente, para los abogados, la asesoría en proyectos de minería se ha venido incrementando exponencialmente, cada año, durante la última década.

Para nadie es un secreto que el Perú se ha vuelto un país muy atractivo para las inversiones mineras, y pese a algunos problemas que se han presentado en los últimos meses, la expectativa es que la inversión en este rubro, que representa una parte importante del Producto Bruto Interno y de las exportaciones, continúe en aumento.

La minería peruana ha logrado captar inversiones por más de US\$18,000 millones en los últimos 15 años, lo que le ha permitido crecer a una tasa superior a la del Producto Bruto Interno nacional' ${ }^{1}$. Además, según datos de la Sociedad Nacional de Minería, Petróleo y Energía, la inversión en minería en el año 2010 ascendió a US\$ 4,025 millones, mientras que según las cifras de la Agencia de Promoción de la Inversión Privada - Prolnversión, en el año 2011 fue de US\$ 5,384 millones, siendo la minería el destino del $24 \%$ de inversiones de capital extranjeras.

Queda bastante claro que las inversiones en minería representan una parte importante en el sector económico del país, siendo principalmente empresas extranjeras y transnacionales las que invierten en la adquisición y explotación de los proyectos mineros. Pero, ¿bajo qué mecanismos se realizan estas adquisiciones? ¿Qué aspectos deben tenerse en cuenta principalmente durante un proceso de adquisición de un proyecto minero? El objetivo del presente trabajo es elaborar una especie de guía para la adquisición de esta clase de proyectos, explicando las estructuras más comunes y aspectos preliminares a evaluar, dependiendo si se busca una adquisición total, parcial o una inversión en determinado proyecto con uno o más socios estratégicos.

\section{TIPOS DE ADQUISICIÓN}

Nuestras legislaciones minera y societaria otorgan una amplia gama de posibilidades para la adquisición de proyectos mineros. Como es imaginable, no necesariamente los inversionistas buscan tener el íntegro de participación en un proyecto minero, sino que muchas veces buscan formar sinergias con el dueño de la concesión, aportando capital, tecnología, experiencia u otros factores en beneficio de ambas partes. Evidentemente, esta última opción también tiene implicancias societarias en el día a día de la empresa, considerando que lo más probable, es que la relación entre las partes sea a largo plazo y no siempre se podrán tomar las decisiones de manera salomónica entre los accionistas. Así, para estos últimos casos, se deben tomar en cuenta otros factores al momento de adquirir, como la suscripción de un pacto de accionistas, contratos de operación, elaboración de estatutos sociales más detallados, entre otros.

Luego de esta explicación preliminar, a continuación pasamos a detallar las estructuras más comunes para la adquisición de proyectos mineros, dependiendo del tipo de adquisición:

\section{Adquisición vía contrato de transferencia de concesiones del proyecto minero}

Como todos sabemos, los proyectos mineros están compuestos de distintas concesiones mineras ubicadas en una zona común. En tal sentido, la primera opción, y más evidente a todas luces, sería celebrar un contrato de transferencia de derechos mineros según lo establecido en el artículo 164 del Texto Único Ordenado de la Ley General de Minería aprobado por el Decreto Supremo 014-92-EM (en adelante, el “TUO").

1. Según el señor Hans Flury, ex Presidente de la Sociedad Nacional de Minería, Petróleo y Energía, El PBI nacional ha crecido 135 por ciento desde 1990, mientras que el PBI minero aumentó en 260 por ciento. 
Al respecto, cabe señalar que la contratación minera se desenvuelve de una manera plena dentro del ámbito del derecho privado. Concordamos con Belaunde ${ }^{2}$ cuando señala que la intervención del Estado es pequeña, y se encuentra circunscrita fundamentalmente a la inscripción del contrato en el Registro de Derechos Mineros de la Superintendencia Nacional de Registros Públicos - SUNARP ${ }^{3}$. A continuación analizaremos los aspectos más relevantes sobre este tipo de adquisición:

\subsection{Sobre el contrato de transferencia de derechos mineros}

El artículo 164 del TUO regula la transferencia de derechos mineros, incluyendo la concesión. El artículo es bastante escueto y directo ${ }^{4}$. Si bien queda claro que se permite la transferencia de derechos mineros, este artículo debe ser leído en concordancia con el artículo 160 del Reglamento de Diversos Títulos del TUO, aprobado por Decreto Supremo 03-94-EM (en adelante, el "Reglamento"), el mismo que dispone que los contratos a que se refiere el Artículo 164 del TUO, son aquellos que implican transferencia de dominio.

Cabe señalar que según el mismo artículo, la transferencia de este derecho comprende las partes integrantes de la concesión y, en su caso, las accesorias, cuando así se pacte expresamente.

Respecto al análisis específico de la restricción a la rescisión por lesión que desarrolla el artículo del TUO bajo comentario, nos referiremos en el punto II.1.c) posterior.

\subsection{Disposiciones formales y generales}

(i) Naturaleza: El artículo 162 del TUO dispone que los contratos mineros 5 se rigen por las reglas del derecho común en todo lo que no se oponga a lo establecido en dicha ley. Esto es, se remite al derecho civil como norma de aplicación general, con excepción de los aspectos propios del derecho de minero que difieran de dicho Código. Además, el artículo 128 del TUO consagra la aplicación supletoria del Código Civil y de la Ley General de Sociedades (en adelante, "LGS") a la contratación minera.

(ii) Formalidad: Según el artículo 163 del TUO, los contratos mineros constarán en escritura pública y deberán inscribirse en el Registro de Derechos Mineros de la SUNARP para que surtan efecto frente al Estado y terceros (el subrayado es nuestro). La consecuencia legal del incumplimiento de la formalidad establecida por ley es claramente la ineficacia del contrato frente a terceros, pero, cabe hacerse válidamente la pregunta sobre la aplicabilidad entre las partes contratantes: ¿es un contrato nulo? ¿anulable? Sobre el particular, concordamos con Belaunde ${ }^{6}$ cuando señala que la formalidad de este tipo de contrato es "ad probationem" y no "ad solemnitatem" , y consecuentemente, si un contrato minero se celebra bajo la forma de contrato privado, o únicamente se suscribe la minuta, más no la escritura pública correspondiente, cualquiera de las partes podría exigir a la otra en base al artículo 1412 del Código Civil, que se completen las formalidades requeridas por ley.

2. BELAUNDE MOREYRA, Martín. Derecho Minero y Concesión. Tercera edición. Lima. Editorial San Marcos E.I.R.L. 2009. pp. 225-226.

3. Sobre el particular, agregaríamos que la intervención, sin dejar de ser mínima, se extendería también a la inscripción del cambio de titularidad ante el Instituto Geológico, Minero y Metalúrgico - INGEMMET.

4. Artículo 164.- En los contratos en los que se transfiera la totalidad o parte de concesiones no hay rescisión por causa de lesión.

5. Entre los que se incluye el contrato de transferencia de derechos mineros.

6. BELAUNDE MOREYRA, Martín. Op. Cit. pp. 226-227.

7. El doctor Belaunde basa su posición en la opinión del doctor Guillermo García Montufar. 


\subsection{Sobre la rescisión por lesión y el derecho de retracto}

Un punto a tener en cuenta desde el lado teórico es la limitación a la aplicación de la figura de la rescisión por lesión en los contratos de transferencia de derechos mineros. Pero, ¿a qué se debe la diferenciación que hace el TUO para el derecho minero frente al Código Civil y el derecho común? Pues bien, al transferir un derecho minero, el objeto jurídico del contrato es la transferencia de la titularidad, a diferencia del contrato de compraventa del derecho civil, en la que se trata de la propiedad. El titular de la concesión tiene un derecho específico otorgado por el Estado, pero éste nunca desprende su dominio originario.

Por otro lado, el Reglamento señala en su artículo 132 que el derecho de retracto no es aplicable a la transferencia de derechos mineros.

Pasamos a analizar estas limitaciones a continuación:

(i) Sobre la lesión: Siguiendo a Moisset de Espanés ${ }^{8}$ la lesión es una institución jurídica que tiene a proteger al débil, al necesitado, a la persona que se encuentra en una situación de inferioridad económica, psíquica o psicológica, frente a aquél que, explotando esa necesidad y aprovechando su situación de superioridad, consigue en un contrato ventajas inicuas. El elemento principal es que una de las partes recibe menos de lo que le corresponde por el objeto del acto jurídico, mientras que, por su parte, otro paga menos de lo debería pagar.

Así, tenemos que el artículo 1447 del Código Civil dispone que la acción rescisoria por lesión sólo puede ejercitarse cuando la desproporción entre las prestaciones al momento de celebrarse el contrato es mayor de las dos quintas partes, y siempre que tal desproporción resulte del aprovechamiento por uno de los contratantes de la necesidad apremiante del otro. Es decir, se requiere la reunión del elemento objetivo (la desproporción) y dos elementos subjetivos a saber (inferioridad de la víctima y aprovechamiento del lesionante).

La lesión ha sido excluida de los contratos de naturaleza minera, principalmente, debido a que hay mucha aleatoriedad respecto al valor real de un contrato de transferencia, dado que no se puede saber con la precisión necesaria las reservas y recursos que podrán ser explotados en la concesión hasta una etapa más avanzada del proyecto, así como los costos que podrían estar asociados a dicho aprovechamiento. Imaginemos el caso de las concesiones en etapa de exploración: Este proceso puede llevar años antes de iniciar finalmente la etapa de explotación, e implica muchos gastos técnicos, operativos, legales, ambientales, entre otros. Además, el resultado, aunque puede ser un poco previsible respecto a la existencia o no de recursos minerales, podría ser negativo desde un punto de vista de proyecciones financieras, con lo cual recién considerando los gastos asociados al negocio y posible retorno con el precio pactado para la transferencia, se podría evaluar si procede la lesión; ello, sin considerar el requisito del aprovechamiento.

(ii) Sobre el retracto: Según el artículo 132 del Reglamento, el retracto no es aplicable a la transferencia de derechos mineros, o de parte de ellos. Al respecto, cabe señalar que este derecho se encuentra regulado en el artículo 1592 del Código Civil. Podemos definir el retracto, pues, como aquel otorgado por la ley a determinadas personas en una especial situación, a fin de sustituirse en el lugar de la persona que ha adquirido la propiedad de un determinado bien?.

8. MOISSET DE ESPANÉS, Luis. Código Civil Comentado. Tomo VII. Segunda Edición. Editorial Gaceta Jurídica. Lima. 2007. pp. 457-458.

9. AMAYA AYALA, Raúl. Código Civil Comentado. Tomo VIII. Segunda Edición. Editorial Gaceta Jurídica. Lima. 2007. pp. 261-262. Se agrega que es un tercero ajeno a una relación jurídica obligacional quien, por mandato de la ley y en 
En este caso, el retracto del Código Civil es aplicable al contrato de compraventa, y por más que "el contrato de transferencia es al derecho minero lo que el contrato de compraventa es al derecho civil ${ }^{10 "}$, la naturaleza de la transferencia, como ya hemos explicado, es diferente, dado que uno se refiere a propiedad, mientras el otro, a titularidad. Esta es una de las razones por las cuales el retracto no es aplicable al derecho minero.

Por otro lado, el Código Civil le otorga un carácter limitativo a su ejercicio, y dichas situaciones deben estar señaladas taxativamente. Además, tiene un carácter excepcional, debido a que el retracto atenta contra la seguridad que debe reinar en la contratación ${ }^{11}$.

\subsection{Sobre la verificación regulatoria de derechos y condiciones asociadas a las concesiones del proyecto}

Al tratarse de la adquisición de un derecho y no de una sociedad objetivo en esta clase de transacción, no es estrictamente necesaria la conducción de una auditoría legal profunda (en adelante, "due diligence"). Sin embargo, sí consideramos necesario incidir en algunos puntos importantes, como por ejemplo si las concesiones que conforman el proyecto se mantienen vigentes, si el titular ha pagado los derechos de vigencia o tiene penalidades pendientes de pago, la verificación de la existencia de restos arqueológicos en la zona, acceso al uso de agua en la zona o preexistencia de un permiso, licencia o autorización (dependiendo del caso) previamente otorgado relacionado al uso de agua, situación del poseedor del terreno superficial de la concesión, titularidad registral, superposición con otras concesiones, relaciones comunitarias, etc.

Estos temas serán abordados más a fondo cuando veamos los aspectos regulatorios relevantes del due diligence en adquisiciones de sociedades titulares de proyectos mineros, a cuya sección hacemos referencia.

\subsection{Tipo de adquisición}

En este caso, la adquisición puede ser tanto total como parcial. No obstante ello, debe tenerse en cuenta que de acuerdo al Reglamento, si se transfiere una alícuota de la concesión, se formaría una cotitularidad sobre cada concesión, lo cual se encuentra prohibido legalmente. Así, según el artículo 131 del Reglamento, se formaría una sociedad legal minera, lo cual puede no ser favorable para un potencial inversionista.

\subsection{Puntos clave sobre la adquisición mediante contrato de transferencia de derechos mineros}

(i) No son aplicables los conceptos de rescisión por lesión y el derecho de retracto, por mandatos expresos del TUO y del Reglamento.

(ii) Se deben verificar previamente en un proceso de due diligence regulatorio los aspectos relacionados a las concesiones, tales como la vigencia de la concesión, existencia de restos arqueológicos en la zona, acceso al uso de agua en la zona o preexistencia de un permiso, licencia o autorización (dependiendo del caso) previamente otorgado relacionado al uso de agua, situación del poseedor del terreno superficial de la concesión, titularidad registral, superposición con otras concesiones, entre otros.

(iii) La transferencia debe inscribirse ante la SUNARP a efectos de ser oponible frente al Estado y terceros.

(iv) Si se adquiere una alícuota de la concesión, se formaría una cotitularidad sobre cada concesión, formándose una sociedad legal minera.

ejercicio de un derecho otorgado, reemplaza al comprador original y asumo dicha posición, así como todas las obligaciones establecidas en el contrato de compraventa.

10. BELAUNDE MOREYRA, Martín. Op. Cit. p. 227.

11. MARTínEZ COCO, Elvira. Citada por AMAYA AYALA, Raúl. Op. Cit. p. 262. 


\section{Adquisición de la sociedad titular del proyecto minero}

El segundo supuesto que explicaremos es bastante más común, e implica la adquisición de las acciones emitidas por una sociedad que es titular de un proyecto minero, mediante la suscripción de un contrato privado de compraventa de acciones. En este supuesto, antes de adquirir la participación total o parcial en la sociedad objetivo, se deberá llevar a cabo un proceso de due diligence sobre la misma, a efectos de determinar la vigencia de las concesiones del proyecto, el cumplimiento con las regulaciones vigentes, posibles contingencias $y$, en base a dichos resultados, poder definir el precio de venta de las acciones como negocio en marcha con mayor certeza.

Sin perjuicio de lo antes mencionado, el proceso de due diligence también se torna sumamente importante en los casos en los que la adquisición se realice vía una estructura de project finance. Así, mientras más completo, claro y comprensivo sea el proceso y los resultados del due diligence, más cómodas se sentirán las instituciones que financien la adquisición del proyecto respecto a los riesgos, siendo la consecuencia directa una mayor probabilidad de obtener una aprobación del crédito con condiciones más favorables para el adquirente ${ }^{12}$.

\subsection{Proceso de due diligence}

Si bien el foco del proceso de due diligence debe ser verificar la información regulatoria de la sociedad objetivo y los aspectos relacionados a las concesiones de las que es titular (siendo este el activo más importante), es conveniente efectuar una revisión general de la información por áreas. A continuación explicaremos las principales áreas de revisión, así como los aspectos más relevantes a tener en cuenta durante dicho proceso para cada una de éstas:

1) Aspectos corporativos: Se debe verificar el cumplimiento por parte de la sociedad de 2011. First Edition. pp. 118-119. las obligaciones societarias correspondientes a su funcionamiento. Lo más común en este tipo de proyectos es que las sociedades titulares de los derechos sobre las concesiones sean vehículos especiales creados para tales fines, por lo que esta revisión no debería representar muchos contratiempos. En todo caso, a un nivel más teórico, también correspondería revisar lo siguiente:

(i) Estados financieros: Si bien esto es un trabajo más indicado para los asesores financieros, es necesario revisarlos desde un punto de vista legal, para, entre otras cosas verificar que la sociedad no se encuentre en ningún supuesto de desequilibrio patrimonial de acuerdo a la LGS.

(ii) Libros de actas y de matrícula de acciones: Es conveniente efectuar una revisión de los acuerdos de las juntas de accionistas y sesiones de directorio de la sociedad, a efectos de detectar posibles contingencias que puedan derivar de los acuerdos. Además, es sumamente importante validar la titularidad de las acciones emitidas por la sociedad objetivo a efectos de constatar la legitimidad de la contraparte en el contrato de compraventa de acciones. Esto último puede validarse revisando la matrícula de acciones de la sociedad, de donde también se desprenderá si las acciones materia de la transacción se encuentran gravadas o poseen alguna carga, así como los pactos de accionistas comunicados a la sociedad objetivo.

(ii) Estatuto social: Si bien en una adquisición total es modificable vía acuerdo de junta de accionistas y en una adquisición parcial debe considerarse la suscripción de un pacto de accionistas, se debe revisar el estatuto social a efec-

12. GERITZ, Mark with assistance from ATO, Tosin and SINGH, Jasmin. Successful delivery of mining projects. Clayton Utz 
tos de verificar que no exista ningún derecho de adquisición preferente o limitación de la transferencia de acciones de los accionistas frente a terceros para, de ser el caso, solicitar las renuncias respectivas antes de celebrar el contrato de compraventa de acciones.

(iv) Existencia de pactos de accionistas: Cuando se adquiere una sociedad totalmente, este aspecto no será tan relevante. Sin embargo, en caso se trate de una adquisición parcial, el adquirente deberá respetar los acuerdos del pacto de accionistas preexistente, a menos que se resuelva y se suscriba uno nuevo con los nuevos titulares de intereses en la sociedad.

(v) Existencia de acciones de inversión: Este es un punto importante a efectos de tener en claro los derechos que se le deben otorgar a esta clase de accionistas según las leyes vigentes, o para tener presente la posibilidad de un eventual canje o redención de estas acciones, a través de los mecanismos previstos en la Ley 28739 de fecha 23 de mayo de 2006 y su reglamento, aprobado por Resolución CONASEV 060-2006-EF-94.10 del 23 de agosto de dicho año ${ }^{13}$.

(vii) Tipo de empresa: Es importante tomar en cuenta si se trata de una empresa que liste en bolsas de valores, ya que de ser este el caso, se deben verificar el cumplimiento de las obligaciones correspondientes a dicha condición.

2) Aspectos contractuales: La revisión de los aspectos contractuales dependerá principalmente del estado en que se encuentre el proyecto. En tal sentido, a manera de ejemplo, si nos encontramos ante un vehículo especialmente constituido a efectos de llevar a cabo determinado proyecto y el due diligence se lleva a cabo apenas se otorga la concesión a dicho vehículo, pues probablemente no exista ningún contrato relevante o material a analizar. Caso distinto es el de una sociedad que lleva unos años realizando labores de exploración, y para ello ha celebrado contratos con empresas de tractores, camiones y contratistas. En este último supuesto, es necesario establecer un monto mínimo de materialidad para la revisión de los contratos. Mientras menor sea el monto de la materialidad, más exhaustiva será la revisión y precisos los resultados del proceso de due diligence. Además, se deben revisar con especial cuidado los contratos de seguro o de financiamiento, en busca de penalidades, mantenimiento de ratios financieros o cláusulas de cambio de control, entre otras.

3 Titularidad de bienes: Es conveniente llevar a cabo un análisis exhaustivo de los bienes muebles e inmuebles de los que sea titular la empresa objetivo. No obstante ello, este ítem, al igual que muchos de este punto, estará sujeto a la naturaleza y antigüedad del negocio de la sociedad. Así, (i) si es un vehículo especialmente creado para ser titular de las concesiones del proyecto, lo más probable es que no sea propietario o, de serlo, se trate de muy pocos bienes; y (ii) si es una sociedad minera que viene operando el proyecto, dependiendo del estado en que se encuentre (e.g. exploración, explotación), podría tener más bienes y, en tal sentido, sería necesaria una revisión más exhaustiva en este punto.

4 Aspectos tributarios: Preliminarmente, se debe verificar el cumplimiento de las obligaciones tributarias, créditos contra el impuesto a la renta, pérdida tributaria, adiciones y deducciones a la renta neta, crédito fiscal, así como si se encuentra sujeto a la recuperación anticipada de IGV.

5 Aspectos laborales: La revisión de los aspectos laborales comprende principalmente la

13. Ley que promueve el canje y redención de acciones de inversión y su reglamento. 
verificación del cumplimiento de las obligaciones formales (planilla y boletas de pago, horario y jornada de trabajo, reglamento interno), contratos de trabajo, convenios colectivos, convenios de modalidad formativa, contratos de intermediación laboral y outsourcing y contratos de locación de servicios. Adicionalmente, se deberá revisar el cumplimiento de las condiciones laborales, como vacaciones, gratificaciones legales, compensación por tiempo de servicios (CTS), horas extras, seguro de vida, asignación familiar, Essalud, cumplimiento del pago de participación en las utilidades, entre otras.

6 Aspectos regulatorios y ambientales: Este es el punto medular del proceso de due diligence en adquisición de proyectos mineros. El término "concesión" puede ser engañoso, debido a que el hecho de tener una concesión no otorga por sí la capacidad para llevar a cabo actividad minera. El cumplimiento de otros requerimientos como la aprobación del instrumento ambiental, la aplicación de la recientemente aprobada ley de la consulta previa, autorizaciones para el uso del agua y del propietario o poseedor del terreno superficial son sólo algunos de los documentos adicionales que son necesarios para operar. A través de esta revisión, se debe determinar con claridad lo siguiente:

(i) La titularidad de la concesión: Esto se puede verificar rápidamente efectuando la búsqueda correspondiente ante la SUNARP e INGEMMET.

(ii) Cumplimiento del pago de derecho de vigencia, penalidad y obligaciones formales: Verificar que la sociedad objetivo haya cumplido con efectuar el pago de los derechos de vigencia correspondientes, ya que el incumplimiento de realizar estos pagos constituye causal de caducidad de la concesión. Así, el monto a pagar dependerá de factores tales como el número de hectáreas de la concesión, del tipo de concesión (metálica o no metálica), si se trata de un pequeño productor minero, etc.

Por otro lado, se tiene que verificar si la sociedad ha cumplido con la producción mínima, de ser el caso, ya que dicho incumplimiento también podría hacer que se declare la caducidad de la concesión.

(iii) Titularidad del terreno superficial sobre el que se encuentra la concesión: este punto es sumamente sensible. Ya sea para actividades de exploración o explotación, es necesario contar con un acuerdo firmado con el propietario o poseedor del terreno superficial de la concesión mediante el cual se autorice al titular a realizar las actividades mineras por un determinado periodo, antes de iniciar dichas actividades ${ }^{14}$. Los propietarios de estos terrenos pueden ser privados, comunidades campesinas o nativas, o el Estado.

En los supuestos en los que el propietario del terreno es un privado o el Estado, es más sencillo obtener los acuerdos debido a que se lleva a cabo un trato directo. No obstante ello, cuando son comunidades campesinas o nativas el panorama es un poco más complicado, considerando que las leyes establecen que las asambleas de comuneros de dichas comunidades tomen el acuerdo correspondiente con 2/3 de aprobación. Muchas veces estas negociaciones toman mucho tiempo debido a (i) las expectativas económicas de la comunidad; y (ii) la eventual falta de organización de la comunidad. En este último caso, no es tan común ver comunidades que tengan al día el padrón de comuneros y que celebren

14 Evidentemente, también cabe la opción de adquirir dichas tierras cuando sea factible. 
las asambleas necesarias, aunque, a decir verdad, estas prácticas se han vuelto más usuales en los últimos años. A falta de acuerdo, el concesionario podría solicitar que se imponga una servidumbre frente al Estado, pero políticamente es poco probable que suceda una situación como tal.

(iv) Instrumento ambiental correspondiente a la actividad: en caso no se haya obtenido, se debe tener en cuenta que dependiendo del tipo de actividad que se pretende realizar, se deberá contar con un Estudio de Impacto Ambiental, un Estudio de Impacto Ambiental Semidetallado o una Declaración de Impacto Ambiental. Al igual que en los casos anteriores, la existencia de un instrumento ambiental aprobado al momento de la adquisición dependerá de si la sociedad objetivo es un vehículo de un proyecto o nuevo, o si, por el contrario, el proyecto se viene realizando hace un tiempo, ya sea en exploración o explotación.

(v) Superposición de la concesión: es importante verificar ante INGEMMET que las concesiones materia del proyecto no se encuentren superpuestas con concesiones de terceras personas, a efectos de evitar posibles contingencias futuras al llevar las actividades de exploración y explotación minera posteriormente.

(vi) Derechos para el uso del agua: Es necesario verificar si la zona en la que se encuentra ubicada la concesión cuenta con acceso a recursos hídricos, y, en todo caso, validar si es que la sociedad no cuenta previamente con algún derecho otorgado sobre dicho recurso. Al respecto, cabe señalar que en el Perú existen tres clases de derechos para el uso del agua: licencias, permisos y autorizaciones, las cuales son otorgadas por la Autoridad Nacional del Agua o la Autoridad Local del Agua correspon- diente. Pasamos a explicar brevemente de qué se trata cada una a efectos de evitar alguna confusión:

- $\quad$ Licencia: Este derecho permite el uso de los recursos hídricos para los propósitos de la actividad minera, con los límites que señale dicho documento. Este derecho es necesario para realizar actividades de explotación minera.

- $\quad$ Permiso: Este derecho está sujeto a la existencia del recurso hídrico después de que los usuarios con licencias y autorizaciones han cubierto la capacidad asignada a ellos en los respectivos documentos.

- $\quad$ Autorización: Este derecho es otorgado usualmente para realizar estudios. No implica necesariamente el otorgamiento de una licencia posterior.

(vii) Consulta previa: Antes de iniciar actividades, se deben cumplir con los requerimientos de la Ley 27985 , "Ley del derecho a la consulta previa a los pueblos indígenas u originarios, reconocido en el Convenio 169 de la Organización Internacional del Trabajo (OIT)".

(viii) Mineros informales: Se debe verificar la zona en relación a la presencia de mineros informales que pudieran perjudicar el desenvolvimiento del negocio de la empresa, o causar daños ambientales atribuibles al negocio.

(ix) Inexistencia de restos arqueológicos/ área natural protegida: Es necesario obtener un certificado de inexistencia de restos arqueológicos ante el Ministerio de Cultura, así como verificar que las concesiones no se encuentren ubicadas sobre un área natural protegida.

(x) Plan de Cierre de Minas: Los cuales será aplicable si ya se iniciaron operaciones, y establece las medidas para mitigar los impactos ambientales durante el

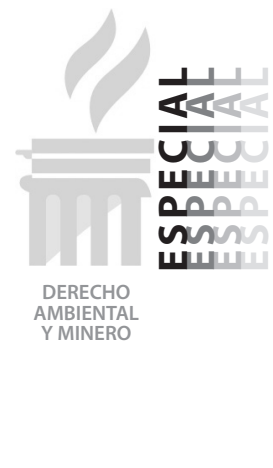


inicio, transcurso y culminación de la actividad que pretende realizarse.

(xi) Permiso de Operación: Este documento es necesario a efectos de iniciar operaciones.

7) Aspectos procesales y de litigios: Evidentemente, es necesario contar con la información de cualquier proceso judicial o arbitral del que sea parte la compañía para que, luego de un análisis, se pueda determinar el grado y monto estimado de la contingencia.

8) Propiedad Intelectual: No siempre es relevante, a menos que además de uno o varios proyectos mineros, también estemos adquiriendo una marca constituida en el mercado.

Una vez analizados dichos aspectos, se puede inferir el nivel de contingencias al momento de la adquisición, y presentar una propuesta con un precio más certero y no se perjudique a la sociedad adquirente.

\subsection{Contrato de compraventa de acciones}

El objeto del contrato es bastante evidente. No obstante, en dicho documento se deben incluir aquellas responsabilidades que quedarán bajo la responsabilidad del vendedor, y definir con claridad cuáles son las obligaciones que asumirá el adquirente. Además, se debe tener extremo cuidado en incluir como declaraciones y garantías del vendedor los aspectos contingentes que se revelen en el proceso de due diligence, o aquellos sobre los cuales no se haya podido obtener o no le hayan proporcionado información.

\subsection{Adquisición parcial: Pacto de accionistas}

1) Sobre el pacto de accionistas

En casos se trate de una adquisición parcial de acciones, y el inversionista decida llevar a cabo el negocio de manera conjunta con el actual titular de las acciones de la sociedad titular del proyecto minero, es sumamente importante que se celebre un pacto de accionistas para regular las relaciones entre éstos durante el tiempo en que desarrollen actividades en la sociedad titular del proyecto.

El pacto de accionistas es un acuerdo entre una pluralidad de socios o accionistas de una misma sociedad mercantil, o entre éstos y terceros, en forma paralela a la organización estatutaria, que tiene por objeto el cumplimiento de determinadas pautas de actuación frente a la propia sociedad, con la finalidad de tutelar los intereses de sus miembros frente a los demás socios o accionistas, o de influir en forma relevante en las decisiones de los órganos de gobierno de la sociedad ${ }^{15}$. Así, lo que se busca es que cada uno de los accionistas resguarde aquellos asuntos de interés mediante derechos de veto, por ejemplo, o exija mayorías menos rigurosas para la toma de determinados acuerdos, siendo éstos oponibles a la sociedad según el artículo 8 de la $\mathrm{LGS}^{16}$. Cabe señalar que las disposiciones del pacto de accionistas no pueden ser contrarias a lo establecido en el pacto social, estatuto de la sociedad o la LGS ${ }^{17}$.

2 Principales aspectos a incluirse en el pacto de accionistas

15. ROSELLÓ DE LA PUENTE, Rafael y OCAMPO VÁZQUEZ, Fernando. La sindicación de acciones. En: Tratado de Derecho Mercantil. Tomo I. 2da edición. Gaceta Jurídica, Lima, 2005, p. 139.

16. Artículo 8.- Convenios entre socios o entre éstos y terceros

Son válidos ante la sociedad y le son exigibles en todo cuanto le sea concerniente, los convenios entre socios o entre éstos y terceros, a partir del momento en que sean debidamente comunicados.

Si hubiera contradicción entre alguna estipulación de dichos convenios y el pacto social o el estatuto, prevalecerán estos últimos, sin perjuicio de la relación que pudiera establecer el convenio entre quienes lo celebraron.

17. Para mayor información sobre la regulación de los pactos de accionistas, nos referimos a DE LA PIEDRA, Ricardo. ¿Hasta que la muerte los separe? Comentarios a la regulación de los convenios parasocietarios. En: Revista Diálogo con la Jurisprudencia No. 144. Editorial Gaceta Jurídica. 2010. pp. 155-165. 
Los principales aspectos que contiene un pacto de accionistas para un proyecto minero son los siguientes:

(i) Políticas de aumentos de capital obligatorios, aporte de fondos y destino de los mismos.

(ii) Derechos de adquisición preferente, tag along, drag along, put options, y otras restricciones a la transferencia de las acciones, que pueden comprender incluso mecanismos de valorización de las acciones para estos casos.

(iii) Derechos de opción para aumentar la participación accionaria en la sociedad, usualmente a cambio de prestaciones adicionales técnicas u operativas a favor de la sociedad por parte de uno de los accionistas experto en el tema.

(iv) Composición del directorio y políticas internas para la designación de directores, lo que puede incluir periodos en que un grupo tenga mayoría en el directorio o pueda designar al Presidente.

(v) Competencia del directorio y de la junta de accionistas para la toma de acuerdos. En estos casos, se establece con precisión qué temas deben ser aprobados por determinado órgano societario (por ejemplo, modificaciones al plan anual de inversiones, aumentos en los costos operativos, aprobación de estudios de factibilidad por un valor superior a " $x$ ", entre otros) sin que sea necesario incluir dichas políticas en un documento público como sí lo es el estatuto social.

(vi) Quórums y mayorías para determinados asuntos, regulaciones para la reunión de los accionistas y directores.

(vii) Derechos de veto para ciertos temas mientras se tenga determinada participación en la sociedad.
(viii)Designación del operador y condiciones del contrato de operación. Usualmente el operador es uno de los accionistas o una empresa vinculada a alguno de éstos.

(ix) Nombramiento de órganos internos adicionales, como comités técnicos, comités operativos, entre otros, dependiendo de las necesidades específicas de cada sociedad.

(x) Derechos y obligaciones especiales.

(xi) Aspectos relativos a la fiscalización y auditoría de las cuentas sociales.

(xii) Custodia de los libros societarios y contables.

(xiii) Términos y condiciones generales aplicables a las ventas.

(xiv)Mecanismos de resolución de disputas.

\subsection{Puntos clave}

Para este tipo de adquisición se debe tener en cuenta lo siguiente:

1) Llevar a cabo un proceso de due diligence a efectos de obtener un análisis de las contingencias asociadas con la eventual adquisición, y así tener una idea más clara del precio a pagar por la sociedad. El grado de rigurosidad y profundidad dependerá de si la adquisición es total o parcial.

2) Celebrar el contrato de compraventa de acciones incluyendo como declaraciones y garantías del vendedor aquellos aspectos contingentes del due diligence, o aquellos puntos en los que el vendedor no haya proporcionado información, o ésta no haya sido posible de obtener. Además, se debe definir con precisión qué obligaciones quedarían eventualmente a cargo del vendedor, así como sus responsabilidades.

3) En caso se trate de una adquisición parcial, es conveniente suscribir un pacto de accio- 
nistas para regular las relaciones entre los accionistas durante el tiempo que dure el proyecto.

\section{Inversión conjunta en el proyecto minero}

Esta es una variante de la adquisición parcial comentada en el punto anterior y es bastante común cuando una sociedad es titular de las concesiones de un proyecto minero y de algunos estudios que acreditan la existencia de recursos minerales en dichas áreas, más no cuenta con el capital o la tecnología necesaria para ejecutar el proyecto. En dichos supuestos, la figura funciona en una forma similar a la adquisición parcial, sólo que en lugar de hacerse una adquisición de las acciones de la sociedad titular del proyecto, (i) el inversionista realiza aumentos de capital en dicha sociedad hasta llegar a un porcentaje acordado; o (ii) se constituye una sociedad vehículo a la cual la sociedad objetivo aporta las concesiones del proyecto, estudios y otros activos relacionados, asignándose un valor sobre el cual se calculará la emisión de acciones correspondiente, mientras que el inversionista aporta capital, tecnología, estudios u otro tipo de bienes (según el acuerdo) a la sociedad vehículo por el monto necesario para llegar a la participación accionaria conforme al acuerdo de las partes. En consecuencia, la sociedad vehículo o holding será la titular de todos los bienes y capital relacionados al proyecto, incluyendo, claro está, las concesiones; y los accionistas participarán en la proporción que comercialmente acuerden.

\subsection{Sobre el proceso due diligence}

(i) Si se utiliza la estructura de una sociedad vehículo y aportes de los socios, el due diligence se deberá centrar principalmente en los aspectos regulatorios de las concesiones que forman el proyecto, según hemos explicado precedentemente.

(ii) Si se utiliza la estructura de aportes de capital a una sociedad ya existente que es titular de las concesiones que con- forman el proyecto, lo recomendable es efectuar un due diligence mucho más riguroso, debido a que se asumirán las contingencias internas que tenga la sociedad objetivo.

\subsection{Sobre el pacto de accionistas}

En ambos supuestos, al tratarse de una "adquisición" parcial, es conveniente la suscripción de un pacto de accionistas para regular las relaciones entre los socios durante el proyecto. Hacemos referencia a nuestra explicación del punto II.2.c) del presente documento sobre los principales aspectos que debería tener el pacto.

\subsection{Puntos clave}

1) La estructuración y rigurosidad del proceso de due diligence dependerá en gran forma del tipo de inversión. Si ésta se realiza vía aportes de capital de ambas partes a una sociedad vehículo especialmente constituida para tales efectos, el due diligence deberá enfocarse más rigurosamente en los aspectos regulatorios relacionados a las concesiones que forman parte del proyecto, mientras que si la inversión se da vía aportes de capital del inversionista a una sociedad ya constituida y con el negocio en marcha, el proceso de due diligence deberá ser riguroso en todos sus aspectos.

2) Independientemente de la forma utilizada, en estos casos la suscripción de un pacto de accionistas bajo las condiciones ya explicadas es bastante recomendable, a efectos de tener las reglas del juego claras respecto a los temas comerciales y legales entre las partes, durante el tiempo que dure su relación como accionistas de la sociedad titular del proyecto.

3) Cabe señalar que estas estructuras no excluyen otras figuras de participación conjunta, tales como asociaciones en participación u otras que pudieran ser aplicables vía contratos de joint venture o colaboración empresarial. 


\section{CONCLUSIONES}

Las principales conclusiones sobre cada tipo de adquisición y los aspectos relevantes a analizar han sido desarrollados bajo el subtítulo de "puntos clave" en cada sección.

El objeto del presente trabajo ha sido efectuar una guía rápida sobre las estructuras más utilizadas para la adquisición de proyectos mineros en el Perú. En tal sentido, no pretende ser una investigación exhaustiva sobre cada una de las actividades a seguir y aspectos a evaluar, ya que un trabajo de dichas magnitudes sería mucho más extenso y desnaturalizaría el fin de este artículo.

Las estructuras desarrolladas en el presente artículo no excluyen otras formas de adquisición de proyectos mineros o de participación conjunta. El objetivo ha sido otorgar una visión resumida de las principales formas de adquisición de proyectos mineros, y los aspectos más relevantes al momento de ejecutarlas. 